\title{
Two Genetically Distinct Populations of Bobtail Squid, Euprymna scolopes, Exist on the Island of $\mathrm{O}^{\prime} \mathrm{ahu}^{1}$
}

\author{
7. R. Kimbell, ${ }^{2}$ M. 7. McFall-Ngai, ${ }^{2}$ and G. K. Roderick ${ }^{3}$
}

\begin{abstract}
Population structure of the endemic Hawaiian bobtail squid, Euprymna scolopes, was examined using both morphological and genetic data. Although allozyme polymorphism was negligible, measurements of eggs, juveniles, and adults, as well as genetic data sequences of mitochondrial cytochrome oxidase I, demonstrated highly significant population structuring between two populations found on the northeastern and southern coasts of the island of O'ahu. These data suggest that extremely low levels of gene flow occur among these populations. Population subdivision of marine shallow-water invertebrates in Hawai' $i$ is not expected based on earlier surveys, but may reflect a more general pattern for organisms, both marine and terrestrial, that exhibit limited dispersal. The subdivision also provides insight into the pathway through which coevolution between $E$. scolopes and its internal symbiont, Vibrio fiscberi, may proceed.
\end{abstract}

The Hawaitan Archipelago presents unique opportunities for the study of evolutionary biology because of its relative isolation, high levels of endemism, and the explosive radiation of a number of taxa ( $\mathrm{Si}-$ mon 1987, Wagner and Funk 1995). For example, the terrestrial invertebrate biota, which has been particularly well studied in genera such as Drosopbila flies, Tetragnatba spiders, and Achatinellinae tree snails, typically exhibits extensive adaptive radiations comprising species endemic to the archipelago (Roderick and Gillespie 1998, Thacker and Hadfield 2000). These patterns are

1 This work was supported by NSF grants IBN $99-$ 04601 to M.M.-N. and E. G. Ruby and DEB 0096189 to R. G. Gillespie and G.K.R., NIH grant RR10926 to E. G. Ruby and M.M.-N., NOAA National SeaGrant R/FM-5 to G.K.R. and C. Smith, and NOAA HCRI grant NA870A0381 to G.K.R. Manuscript accepted 28 November 2001.

2 Pacific Biomedical Research Center, University of Hawai'i, 41 'Āhui Street, Honolulu, Hawai'i 96816.

3 Corresponding author: Department of Environmental Science, Policy, and Management, University of California, 201 Wellman Hall MC 3112, Berkeley, California 94708-3112 (phone: 510-642-3327; fax: 510-6427428; E-mail: roderick@nature.berkeley.edu).

Pacific Science (2002), vol. 56, no. 3:347-355 (C) 2002 by University of Hawai'i Press

All rights reserved thought to result from the extremely heterogeneous nature of the terrestrial island landscape, which presents an abundance of spatially limited, yet distinct, niches ripe for adaptive radiation (Gillespie et al. 2001).

Marine invertebrates, however, have much lower rates of endemism than their terrestrial counterparts, with endemism ranging from 2 to $20 \%$ for nearshore gastropods, brachyuran decapods, and certain polychaetes and echinoderms of the central Pacific (Scheltema 1986, Kay and Palumbi 1987). These benthic marine invertebrates appear instead to represent attenuated Indo-Pacific fauna, and the marine endemic species that do exist are usually distributed throughout all of the islands of the archipelago (Scheltema 1986). The wide geographic distributions of these marine invertebrate species indicate that fairly high gene flow must be occurring between populations within species (Palumbi 1992). Such gene flow is presumably facilitated by long planktonic larval phases, which ensure high dispersal. Yet, within such widespread species some population structure may nevertheless persist (Barber et al. 2000).

Although much is known about marine invertebrate species with extended larval life histories, less is understood about species that do not have broadly dispersing larval or juvenile stages. One such species is the bobtail squid, Euprymna scolopes, which is endemic to 
the Hawaiian Islands (Singley 1983). Female E. scolopes lay clutches of eggs on hard substrates in the shallow waters of the back reef. No true larval stages occur in this species (i.e., the juveniles hatch with a morphology and behavior very similar to those of the adult [Arnold et al. 1972]). Specifically, after a brief planktonic stage of hours to a few days, the juvenile squid take on the diel pattern of behavior characteristic of the species (i.e., they bury in the sand during the day and forage in the water column at night).

Previously, it was observed that E. scolopes is notable for its habitat loyalty, and it has been suggested that two reproductively isolated populations exist on northeastern and southern coasts of the island of $\mathrm{O}^{6} \mathrm{ahu}$ (Singley 1983). The E. scolopes-Vibrio fiscberi association has become a model for animalbacterial symbiosis and in particular the persistent colonization of animal epithelia by extracellular bacteria (McFall-Ngai and Ruby 1998). Recent studies of the squid-vibrio symbioses at the level of species have provided strong evidence for coevolution of the host and symbiont (Nishiguchi et al. 1998). Whether population subdivision of $E$. scolopes exists is critical to understanding the coevolution of this species with its bacteria partners-how isolated are populations of $E$. scolopes and at what scale would populationspecific strains of $V$. fischeri be expected to evolve? In this study we tested the hypothesis of population subdivision of $E$. scolopes with both morphological and genetic data. Our results indicate that populations of $E$. scolopes on $\mathrm{O}^{\prime} \mathrm{ahu}$ are indeed distinct. Further, the results demonstrate that at least some species of Hawaiian marine invertebrates are more subdivided than previously realized, likely as a consequence of a life history lacking dispersive egg or larval stages.

\section{MATERIALS AND METHODS}

\section{Capture and Maintenance of Specimens}

Adult Euprymna scolopes were collected in 1997 and 1998 from two sites, the shallow sand flats off Niu Valley along leeward O'ahu and along the shores of Kāne'ohe Bay on

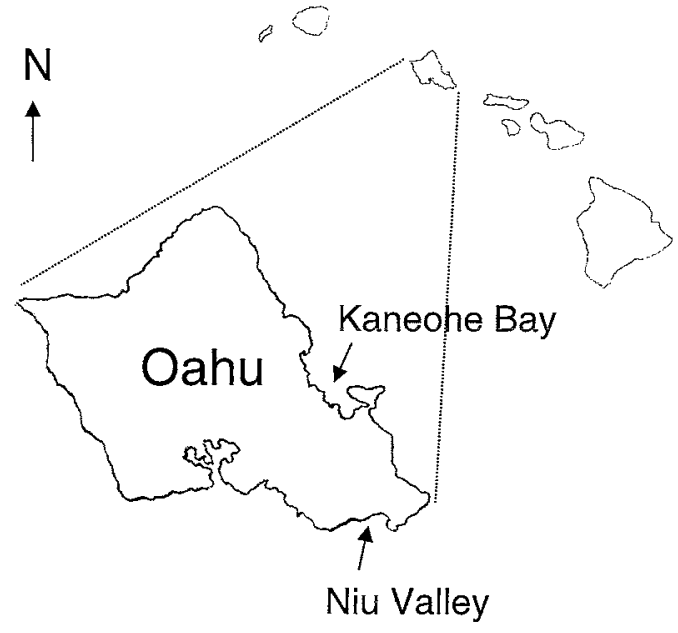

Figure 1. Collection sites on $\mathrm{O}^{\prime}$ ahu, Hawaiian Archipelago, for specimens examined in this study.

windward O'ahu (Figure 1). Specimens were maintained in running seawater tables at $24^{\circ} \mathrm{C}$ at the Kewalo Marine Laboratory, University of Hawai'i.

\section{Morphometric Data}

Measurements of morphological characters were performed to determine whether significant phenotypic differences occur between Kāne'ohe Bay and Niu Valley animals. Three characters were measured on specimens from each of these two sites: female mantle length, egg diameter, and hatchling mantle length. The latter two measurements were made using a dissection microscope (Wild M5) at $10 \times$ with an ocular micrometer. Eggs were measured on the day that they were laid. The hatchlings were first anesthetized in a 50:50 solution of $0.37 \mathrm{M} \mathrm{MgCl}$ : seawater before the mantle-length measurements were taken. Approximately 75 specimens were examined for each character per locality.

\section{Allozymes: Cellulose Acetate Gel Electrophoresis}

Variation at allozyme loci was examined through cellulose acetate gel electrophoresis, a method that requires very little tissue (Richardson et al. 1986, Hebert and Beaton 
1989). Squid tissue was frozen in liquid nitrogen and stored at $-80^{\circ} \mathrm{C}$ until used in analyses. Mantle tissue, because it is of low yield, and light organs, because they contain symbionts, were removed before homogenization. Tissue samples $(0.5 \mathrm{~g})$ were placed on ice and homogenized in an equal volume of distilled water. The homogenates were centrifuged for $5 \mathrm{~min}$ at $12,000 \times \mathrm{g}$ at $4^{\circ} \mathrm{C}$ to pellet tissue debris. Supernatant fluids were placed in microcentrifuge tubes on ice until use. Allozyme electrophoresis was run on cellulose acetate gels in electrophoresis chambers (Zip-zone, Helena Laboratories Inc., Beaumont, Texas). The histochemical staining recipes used were given in Hebert and Beaton (1989). Two buffer systems resulted in the best resolution: "tris-glycine"- $0.4 \mathrm{M}$ Tris with $2 \mathrm{M}$ glycine, $\mathrm{pH} 8.5$, with gel/buffer dilution 1:9; and "tris-maleate" $-0.1 \mathrm{M}$ trismaleate, $\mathrm{pH}$ 7.8. Of the 18 presumed enzymes assayed 7 yielded acceptable enzyme activity and clear resolution: isocitrate dehydrogenase (IDH; E.C. 1.1.1.42), malate dehydrogenase (MDH; E.C. 1.1.1.37), malate dehydrogenase NADP + (ME; E.C. 1.1.1.40), glucose-6-phosphate isomerase (GPI; E.C. 5.3.1.9), mannose-6-phosphate isomerase (MPI; E.C. 5.3.1.8), phosphoglucomutase (PGM; E.C. 5.4.2.2), and aspartate amino transferase (AAT; E.C. 2.6.1.1). The trisglycine buffer was used for PGM and ME, and the remaining loci were run with trismaleate. Horizontal gels were run at $180 \mathrm{~V}$ and $3 \mathrm{~mA}$ for $45 \mathrm{~min}$ at $4^{\circ} \mathrm{C}$. Approximately 30 alleles were scored at each locus for 20 individuals from each locality.

\section{Mitochondrial DNA: Cytochrome Oxidase I}

Squid DNA was extracted from frozen testis tissue (25 mg) with a Qiagen QIAamp Tissue Kit (cat. no. 29304). The isolated genomic DNA was reprecipitated with $95 \%$ ethanol, washed with $70 \%$ ethanol, and resuspended in TE buffer $(10 \mathrm{mM}$ Tris- $\mathrm{HCl}$ and $1 \mathrm{mM}$ EDTA, $\mathrm{pH}$ 8.0). A polymerase chain reaction (PCR) was used to produce DNA templates for the sequencing of the mitochondrial cytochrome oxidase I (COI) gene. Each 50- $\mu 1$ PCR reaction contained $4 \mu \mathrm{g}$ of template
DNA, $0.4 \mu \mathrm{M}$ of each primer, $5 \mu \mathrm{l}$ of $8 \mathrm{mM}$ dNTPs, and $0.12 \mu \mathrm{l}$ of Taq polymerase (Perkin Elmer, Norwalk, California). Amplifications were performed using a thermocycler (GeneAmp PCR 9600). The PCR conditions were as follows: 35 cycles of $94^{\circ} \mathrm{C}$ for $30 \mathrm{sec}$, $47^{\circ} \mathrm{C}$ for $30 \mathrm{sec}$, and $72^{\circ} \mathrm{C}$ for $60 \mathrm{sec}$. The primers used to amplify COI were C1-J-1718 (26 mer, 5'-GGAGGATTTGGAAATTGATTAGTTCC-3') and C1-N-2191 (alias "Nancy" 26 mer, 5'-CCCGGTAAAATTAAAATATAAACTTC-3') (primer designations given in Simon et al. [1994]). The resulting PCR products were purified with a GeneClean Kit (Bio 101 Inc., La Jolla, California). Seven microliters of the resultant DNA and $4 \mu \mathrm{l}$ of $1 \mu M$ C1-J-1718 primer were used for cycle sequencing using the PRISM Ready Reaction Terminator Cycle Sequencing Kit with an ABI Model No. 377 automated sequencer (PE Applied Biosystems, Foster City, California). A total of 18 COI sequences was obtained from 10 individuals from $\mathrm{Ka}$ ne' ohe Bay and 8 individuals from Niu Valley. All DNA sequences were examined and aligned using Sequencher 3.1 (GeneCodes, Ann Arbor, Michigan).

\section{Pbylogeograpbic Analysis}

The evolutionary history of the alleles at a locus can be represented in a phylogenetic tree, which can then be interpreted in light of the geographical distribution of those alleles; this approach is termed phylogeography (Avise 2000). The interpretation of such an analysis can be complicated for nuclear loci because of recombination (Begun and Aquadro 1992, Hudson 1994) and for both nuclear and mitochondrial loci because of the persistence of ancestral alleles (Templeton and Sing 1993). There is no evidence that mitochondrial sequences in this species recombine, yet persistence of ancestral alleles is an issue. Templeton et al. (1992) and Templeton and Sing (1993) provided a method for examining the recent history of alleles at a locus. The method focuses phylogenetic reconstruction on the most recent substitutions before attempting to resolve deeper nodes. Assuming that more recent changes are less likely to in- 
clude homoplasy or recombination, sequences separated by one substitution are linked first, the resulting groups form the basis for linking alleles separated by two substitutions, and so on. Details of the method are provided by Templeton and Sing (1993), Templeton (1998), Davies et al. (1999), and Posada and Crandall (2001).

\section{Population Analysis}

Population structure was determined through the analysis of molecular variation (AMOVA) method of Excoffier et al. (1992) as implemented by the computer program Arlequin 2.0 (Schneider et al. 2000). Indices of population subdivision analogous to standard $F$ statistics (Wright 1951, 1965) were calculated with significance assessed using permutation procedures that randomly redistribute individuals among populations. This general approach was used to estimate $F$ statistics based upon (1) allele frequencies only, and (2) the genetic distance among alleles as well as their frequencies. The $F$ statistics used were (1) $\theta$ (Weir and Cockerham 1984, see Excoffier et al. 1992), and (2) $\Phi$, calculated using the average Kimura 2-parameter distance observed between alleles. Exact tests were performed based on the distribution among populations of (1) alleles and (2) phylogenetically derived allele groups (TFPGA, Miller 1998). In the latter case, alleles in the same one-step clade of the Templeton networks were pooled.

\section{RESULTS}

Significant differences were found among populations for both morphological and genetic characters. Niu Valley females were highly significantly larger and produced highly significantly larger eggs and hatchlings than Kāne'ohe Bay females (Figure 2), supporting Singley's (1983) earlier observations. Although phenotypic differences between the two populations do not provide direct evidence of genetic, or inherited, differences between the two populations, such data are certainly consistent with this hypothesis of genetic differentiation. The life history im- plications of differing egg and female body sizes among these populations have not yet been examined.

The seven enzyme stains resolved nine enzyme-coding loci (IDH and AAT each stained for two loci). All loci examined were monomorphic. Though surprising, this result is not unexpected for squid-other intra/ interspecific studies of squid population structure have yielded negligible allozyme polymorphism and in some cases monomorphism (Brierley et al. 1993, 1995, Izuka et al. 1996). However, other allozyme studies have distinguished among closely related squid species (Izuka et al. 1994) and seasonal cohorts (Kang et al. 1996). Although allozyme data collected here contribute no information concerning the hypothesis of distinct populations, they do raise a question for future work: to what extent does selection contribute to the lack of variation in squid electrophoretic proteins?

Partial COI sequences of approximately 430 base pairs from both Niu Valley and Kāne'ohe Bay animals were obtained. Ten sequences from Kāne'ohe Bay and eight from Niu Valley were resolved. Measures of gene diversity, mean number of pairwise differences, and base composition were very similar in the two populations (Table 1). Our results yielded six distinct haplotypes distinguished by seven polymorphic sites, with only one haplotype being shared among the two populations (Figure 3).

Statistical analysis revealed significant population structure between the populations. Both frequency- and distance-based $F$ statistics were highly significant, with the distancebased estimates, $\Phi(0.60)$, being considerably larger than the frequency-based $\theta(0.49)(\mathrm{Ta}-$ ble 2), illustrating that the sequence data do provide additional information with regard to population structuring in this species.

The values of both $F$ statistics are extremely high, especially considering the small distance between populations. These data, coupled with the observation of only one shared haplotype between the populations (frequency of approximately $10 \%$ in each population), suggest that gene flow is minimal between these 

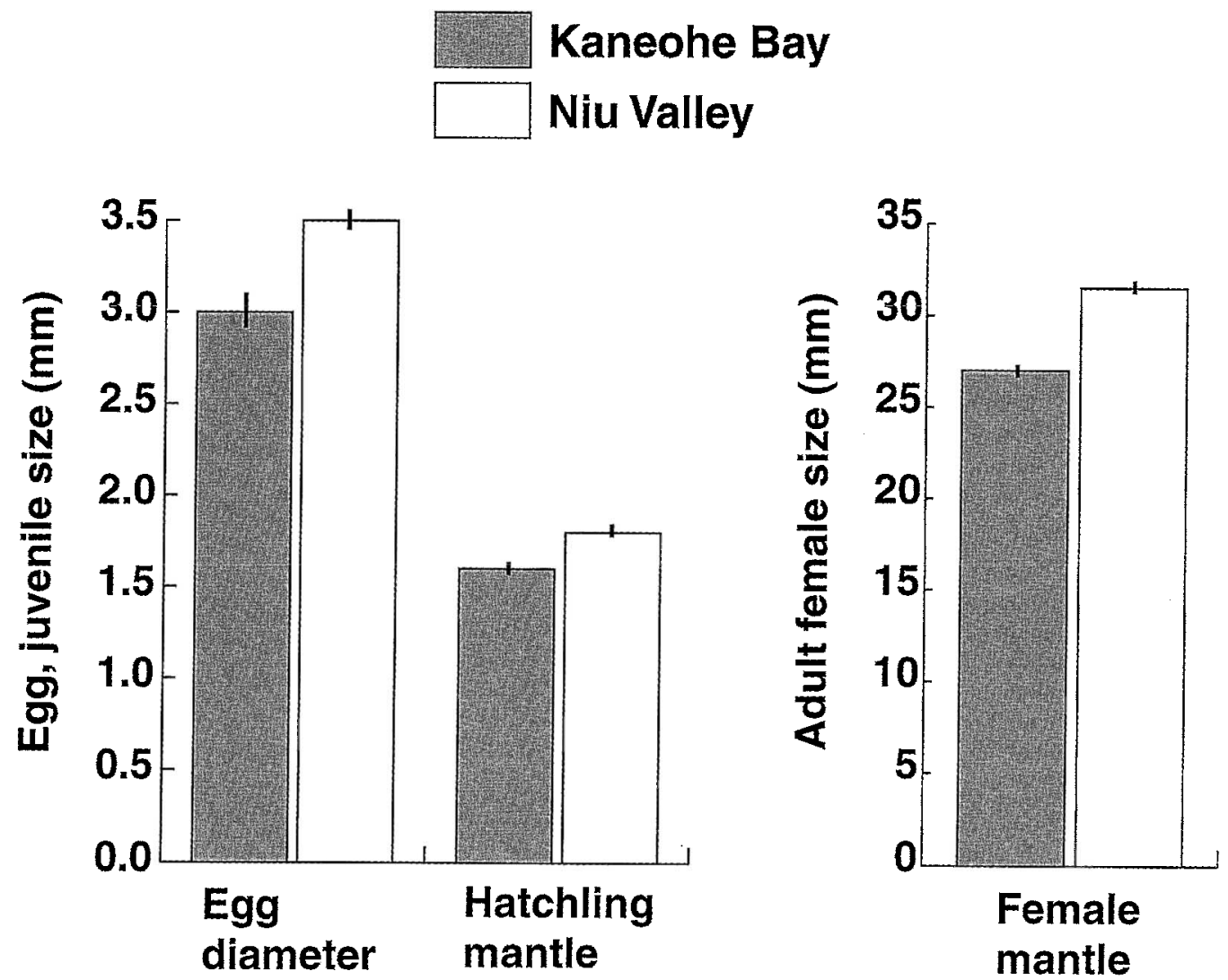

FIgURE 2. Morphological differences among individuals collected in Kăne'ohe Bay and Niu Valley locations. Sample sizes were for eggs, hatchlings, and females $(78,62$, and 30 , respectively) for each population. All comparisons were highly statistically significant $(t$-tests, $P<0.001)$. Female age was uncertain; females were measured the day after dying in the laboratory.

two populations. Using the standard migration estimator for mitochondrial data (Slatkin 1994), migration between these two populations is calculated as approximately one migrant exchanged between the populations only every two to three generations, with a generation time of 3 to 4 months. This effective rate of migration is very low, yet it is still sufficient to prevent complete divergence between the populations by genetic drift alone. It should be noted that this estimate of gene flow should be considered an upper estimatethe two populations may also show some genetic similarity, if they share a recent history (see Bohonak 1999, Bohonak and Roderick 2001).

\section{DISCUSSION}

The analysis of both morphological and genetic data indicates that populations of $E$. scolopes on $\mathrm{O}^{\prime}$ ahu are extremely subdivided, likely exchanging very few, if any, migrants, each generation. The extent to which other populations of $E$. scolopes are so subdivided in Hawai'i is clearly important and well worth investigating. Kāne ohe Bay is surrounded by the only true barrier reef in the Hawaiian Islands (Kay and Palumbi 1987), and it may be that the well-studied Kāne'ohe Bay population is an anomaly. Yet, water does flow actively in and out of the bay.

Subdivision of the E. scolopes populations 


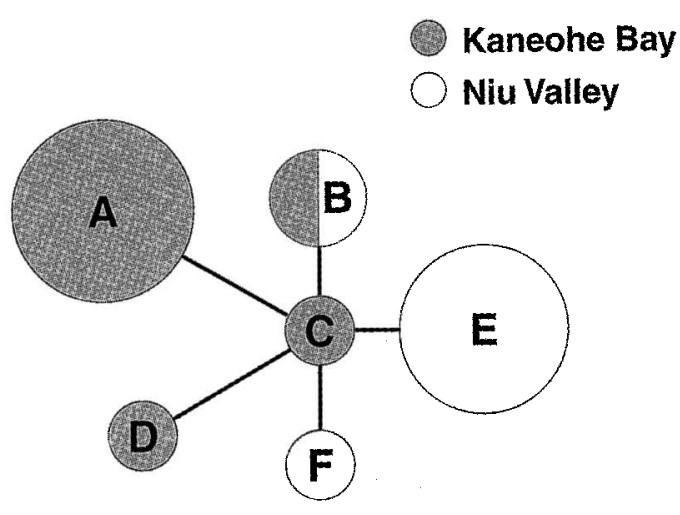

Figure 3. Mitochondrial haplotype network and localities as estimated by the method described by Templeton (1998). Haplotype identities are noted within circles with a letter, and distances between haplotypes are proportional to the number of base pair differences (one or two steps) between haplotypes. The size of the circles is proportional to the number of individuals $(n=18)$ sharing a particular haplotype.

has implications beyond the species. If the level of subdivision observed here is found elsewhere, one can also ask, at what level of divergence does one see a concomitant change in the symbiont Vibrio fischeri? At the mechanistic level, under these very refined con- ditions, one may be able to pinpoint those traits (likely to be cell surface determinants on the host or symbiont) that change as the partners coevolve and become, as a unit, genetically distinct from their congeneric squidbacteria counterparts. For example, symbionts of Japanese squid E. morse infect Hawaiian $E$. scolopes easily by themselves, but quickly lose in competition with the native Hawaiian strain (Nishiguchi et al. 1998). This competitive difference was easily determined because $E$. morsei strains of $V$. fischeri are brightly luminous in culture, whereas $E$. scolopes strains are dim in culture. Thus, when symbiotic organs of such competition experiments are plated on agar, the ratio of the two strains is easily determined. Unfortunately, all isolated strains of $V$. fischeri from Hawai $i$ are dim in culture and, therefore, to compete the symbionts of Hawaiian populations of $E$. scolopes would require genetic engineering of $V$. fischeri strains to introduce distinguishing genetic markers.

The extent of population structure is also important in determining whether host isolation occurs before symbiont isolation or vice versa, or whether host and symbiont track each other closely. The numbers of $V$. fischeri

TABLE 1

Within- and Between-Population Comparisons of Mitochondrial COI DNA Sequences

\begin{tabular}{|c|c|c|c|c|c|c|c|c|c|}
\hline \multirow[b]{3}{*}{ Haplotype Data } & \multicolumn{2}{|c|}{ Locality } & & & & & & & \\
\hline & \multirow{2}{*}{$\begin{array}{c}\text { Kāne'ohe } \\
\text { Bay }(n=10) \\
\text { Frequency }\end{array}$} & \multirow{2}{*}{$\begin{array}{l}\begin{array}{c}\text { Niu Valley } \\
(n=8)\end{array} \\
\text { Frequency }\end{array}$} & \multicolumn{7}{|c|}{ Base Position ${ }^{a}$} \\
\hline & & & 101 & 158 & 263 & 296 & 377 & 389 & 392 \\
\hline A & 0.700 & 0.000 & G & $\mathrm{G}$ & G & A & $\mathrm{T}$ & $\mathrm{T}$ & A \\
\hline B & 0.100 & 0.125 & . & . & A & . & $\mathrm{C}$ & . & . \\
\hline $\mathrm{C}$ & 0.100 & 0.000 & . & . & . & . & . & $\mathrm{C}$ & . \\
\hline $\mathrm{D}$ & 0.100 & 0.000 & . & . & . & G & . & . & . \\
\hline $\mathrm{E}$ & 0.000 & 0.750 & A & . & . & . & . & . & G \\
\hline $\mathrm{F}$ & 0.000 & 0.125 & . & A & . & . & . & . & . \\
\hline Gene diversity & $0.53 \pm 0.18$ & $0.46 \pm 0.20$ & & & & & & & \\
\hline Mean no. pairwise differences & $1.32 \pm 0.89$ & $0.93 \pm 0.71$ & & & & & & & \\
\hline \multicolumn{10}{|l|}{ Nucleotide composition (\%) } \\
\hline $\mathrm{C}$ & 20.7 & 20.4 & & & & & & & \\
\hline $\mathrm{T}$ & 35.8 & 36.0 & & & & & & & \\
\hline A & 27.4 & 27.3 & & & & & & & \\
\hline G & 16.1 & 16.2 & & & & & & & \\
\hline
\end{tabular}

${ }^{a}$ Differences in base positions are shown relative to a reference haplotype (A), with identities shown by ".". 
TABLE 2

$F$ Statistics and Exact Tests for Population Differentiation

\begin{tabular}{lcc}
\hline \hline Method & $F$ & $P$ \\
\hline Frequency $(\theta)$ & .492 & $<0.00001$ \\
Distance $(\Phi)$ & .604 & $<0.00001$ \\
\hline
\end{tabular}

Note: Statistics are presented that are based solely on the frequency of alleles $(\theta)$ and that also consider the genetic distance among alleles $(\Phi)$.

in the water are strongly dependent on the density of host squid in the environment (Lee and Ruby 1994). Thus, at the mouth of Kāne'ohe Bay, where there are few hosts, there are very few $V$. fischeri. There may also be little genetic exchange between symbiont populations.

In sum, populations of $E$. scolopes on two sides of O'ahu are more distinct than previously realized, suggesting that gene flow may be substantially limited in some marine species in Hawai'i. This result likely reflects the lack of long-lived pelagic larvae. Further, the Hawai'i populations of $E$. scolopes and their symbionts offer some interesting opportunities to gain insight into the coevolution of bacteria and their animal hosts. Evidence that the host populations can be extremely subdivided is an intriguing start.

\section{ACKNOWLEDGMENTS}

We thank two anonymous reviewers for helpful and insightful comments.

\section{Literature Cited}

Arnold, J., C. Singley, and L. WilliamsArnold. 1972. Embryonic development and post-hatching survival of the sepiolid squid Euprymna scolopes under laboratory conditions. Veliger 14:361-364.

Avise, J. C. 2000. Phylogeography: The history and formation of species. Harvard University Press, Cambridge, Massachusetts.

Barber, P. H., S. R. Palumbi, M. V. Erdmann, and M. K. Moosa. 2000. A marine
Wallace's line? Nature (Lond.) 406:692693.

Begun, D. J., and C. F. Aquadro. 1992. Levels of naturally occurring DNA polymorphism correlate with recombination rates in $D$. melanogaster. Nature (Lond.) 356:519-520.

Bohonak, A. J. 1999. Dispersal, gene flow, and population structure. Q. Rev. Biol. $74: 21-45$.

Bohonak, A. J., and G. K. Roderick. 2001. Dispersal of invertebrates among temporary ponds: Are genetic estimates accurate? Isr. J. Zool. (in press).

Brierley, A. S., P. G. Rodhouse, J. P. Thorpe, and M. R. Clarke. 1993. Genetic evidence of population heterogeneity and cryptic speciation in the ommastrephid squid Martialia byadesi from the Patagonian Shelf and Antarctic Polar Frontal Zone. Mar. Biol. (Berl.) 116:593-602.

Brierley, A. S., J. P. Thorpe, G. J. Pierce, M. R. Clarke, and P. R. Boyle. 1995. Genetic variation in the neritic squid Loligo fobesi (Myopsida: Loliginidae) in the northeast Atlantic Ocean. Mar. Biol. (Berl.) 122:79_ 86.

Davies, N., F. X. Villablanca, and G. K. Roderick. 1999. Bioinvasions of the medfly, Ceratitis capitata: Source estimation using DNA sequences at multiple intron loci. Genetics 153:351-360.

Excoffier, L., P. Smouse, and J. Quattro. 1992. Analysis of molecular variance inferred from metric distances among DNA haplotypes: Application to human mitochondrial DNA restriction data. Genetics 131:479-491.

Gillespie, R. G., F. G. Howarth, and G. K. Roderick. 2001. Adaptive radiation. Pages 25-44 in S. A. Levin, ed. Encyclopedia of biodiversity. Academic Press, New York.

Hebert, P. D. N., and M. J. Beaton. 1989. Methodologies for allozyme analysis using cellulose acetate electrophoresis. Helena Laboratories, Beaumont, Texas.

Hudson, R. R. 1994. How can the low levels of DNA sequence variation in regions of the Drosopbila genome with low recombination rates be explained. Proc. Natl. Acad. Sci. U.S.A. 91:6815-6818.

Izuka, T., S. Segawa, T. Okutani, and K.-I. 
Numachi. 1994. Evidence on the existence of three species in the oval squid Sepioteuthis lessoniana complex in Ishigaki Island, Okinawa, southwestern Japan, by isozyme analyses. Venus Jpn. J. Malacol. 53:217228.

Izuka, T., S. Segawa, and T. Okutani. 1996. Biochemical study of the population heterogeneity and distribution of the oval squid Sepioteutbis lessoniana complex in southwestern Japan. Am. Malacol. Bull. 12:129-135.

Kang, Y.-J., Y.-H. Kim, Y.-K. Hong, J.-Y. Park, and K.-Y. Park. 1996. A population genetic analysis of the common squid, Todarodes pacificus Steenstrup in the Korean waters. J. Korean Fish. Soc. 29:320331.

Kay, A. E., and S. R. Palumbi. 1987. Endemism and evolution in Hawaiian marine invertebrates. Trends Ecol. Evol. 2:183186.

Lee, K.-H., and E. G. Ruby. 1994. Effect of the squid host on the abundance and distribution of symbiotic Vibrio fischeri in nature. Appl. Environ. Microbiol. 60:15651571.

McFall-Ngai, M. J., and E. G. Ruby. 1998. Sepiolids and vibrios: When first they meet. BioScience 48:257-265.

Miller, M. P. 1998. Tools for population genetic analysis. v. 1.3. Northern Arizona State University, Flagstaff.

Nishiguchi, M. K., E. G. Ruby, and M. J. McFall-Ngai. 1998. Competitive dominance among strains of luminous bacteria provides an unusual form of evidence for parallel evolution in the sepiolid squidvibrio symbiosis. Appl. Environ. Microbiol. 64:3209-3213.

Palumbi, S. R. 1992. Marine speciation on a small planet. Trends Ecol. Evol. 7:114118.

Posada, D., and K. A. Crandall. 2001. Intraspecific gene genealogies: Trees grafting into networks. Trends Ecol. Evol. 16:3745.

Richardson, B. J., P. R. Baverstock, and M. Adams. 1986. Allozyme electrophoresis. Academic Press, New York.

Roderick, G. K., and R. G. Gillespie. 1998.
Speciation and phylogeography of $\mathrm{Ha}-$ waiian terrestrial arthropods. Mol. Ecol. 7:519-531.

Scheltema, R. S. 1986. Long-distance dispersal by planktonic larvae of shoal-water benthic invertebrates among central $\mathrm{Pa}$ cific islands. Bull. Mar. Sci. 39:241-256.

Schneider, S., D. Roessli, and L. Excoffier. 2000. Arlequin: A software for population genetic data analysis. v. 2.00. University of Geneva (distributed on web: http:// anthropologie.unige.ch/arlequin,).

Simon, C. 1987. Hawaiian evolutionary biology: An introduction. Trends Ecol. Evol. 2:175-178.

Simon, C., F. Fratti, A. Beckenbach, B. Crespi, H. Liu, and P. Flook. 1994. Evolution, weighting, and phylogentic utility of mitochondrial gene sequences and a compilation of conserved polymerase chain reaction primers. Ann. Entomol. Soc. Am. 87:651-701.

Singley, C. T. 1983. Euprymna scolopes. Pages 69-74 in P. R. Boyle, ed. Cephalopod life cycles. Academic Press, London.

Slatkin, M. 1994. Gene flow and population structure. Pages 3-17 in L. A. Real, ed. Ecological genetics. Princeton University Press, Princeton, New Jersey.

Templeton, A. R. 1998. Nested clade analysis of phylogeographic data: Testing hypotheses about gene flow and population history. Mol. Ecol. 7:381-397.

Templeton, A. R., and C. F. Sing. 1993. A cladistic analysis of phenotypic associations with haplotypes inferred from restriction endonuclease mapping. IV. Nested analyses with cladogram uncertainty and recombination. Genetics 134:659-669.

Templeton, A. R., K. A. Crandall, and C. F. Sing. 1992. A cladistic analysis of phenotypic associations with haplotypes inferred from restriction endonuclease mapping and DNA sequence data. III. Cladogram estimation. Genetics 132:619-633.

Thacker, R. W., and M. G. Hadfield. 2000. Mitochondrial phylogeny of extant $\mathrm{Ha}$ waiian tree snails (Achatinellinae). Mol. Phylogenet. Evol. 16:263-270.

Wagner, W. L., and V. A. Funk, eds. 1995. Hawaiian biogeography: Evolution on a 
hot spot archipelago. Smithsonian Institu- Wright, S. 1951. The genetical structure of tion Press, Washington.

Weir, B. S., and C. C. Cockerham. 1984. Estimating $\mathrm{F}$-statistics for the analysis of population structure. Evolution 38:13581370. populations. Ann. Eugen. 15:323-354.

1965. The interpretation of population structure by F-statistics with special regard to systems of mating. Evolution 19:395-420. 